\title{
UNDERSTANDING THE SPATIO-TEMPORAL PATTERN OF FIRE DISTURBANCE IN THE EASTERN MONGOLIA USING MODIS PRODUCT
}

\author{
Wurihan $^{1}$, Hongyan Zhang ${ }^{1}$, Zhengxiang Zhang ${ }^{1}$, Xiaoyi Guo ${ }^{1 *}$, Jianjun Zhao ${ }^{1}$, Duwala ${ }^{2}$, Yu Shan ${ }^{1,3}$, Hongying ${ }^{1}$ \\ ${ }^{1}$ School of Geographical Sciences, Northeast Normal University, Changchun 130024, China-(wurh651, zhy, guoxy914, \\ hongy864)@nenu.edu.cn \\ ${ }^{2}$ Inner Mongolia Ecological and Agricultural Meteorological Center, Hohhot 010051, China-dwlrsgis@ 163.com \\ ${ }^{3}$ Inner Mongolia Normal University, Key Laboratory of Remote Sensing and Geographic Information, Hohhot 010022, China- \\ yushangis@163.com
}

KEY WORDS: Spatio-Temporal Pattern, Fire Disturbance, Eastern Mongolia, MODIS Product, Natural Level

\begin{abstract}
:
Fire disturbance plays an important role in maintaining ecological balance, biodiversity and self-renewal. In this paper, the spatiotemporal pattern of fire disturbances in eastern Mongolia are studied by using the ArcGIS spatial analysis method, using the MCD45A1 data of MODIS fire products with long time series. It provides scientific basis and reference for the regional ecological environment security construction and international ecological security. Research indicates: (1) The fire disturbance in eastern Mongolia has obvious high and low peak interleaving phenomenon in the year, and the seasonal change is obvious. (2) The distribution pattern of fire disturbance in eastern Mongolia is aggregated, which indicates that the fire disturbance is not random and it is caused by certain influence. (3) Fire disturbance is mainly distributed in the eastern province of Mongolia, the border between China and Mongolia and the northern forest area of Sukhbaatar province. (4) The fire disturbance in the eastern part of the study area is strong and the southwest is weaker. The spreading regularity of fire disturbances in eastern Mongolia is closer to the natural level of ecosystem.
\end{abstract}

\section{INTRODUCTION}

In the ecosystem management, the main concern is its destructive, harmfulness, and with the continuous improvement of ecological theory and technology, people gradually realize the significance of various disturbances to the ecosystem. Fire disturbance plays an important role in maintaining the balance of ecosystem, biodiversity and the self-renewal of the ecosystem. According to Pickett et al. Interference is an unpredictable event that can occur in natural phenomena in different spatio-temporal pattern. In general, ecosystems evolve in alignment with natural directions, interfering with accelerating updates or blocking updates. The impact of fire disturbance on ecosystems is divided into two categories: the first is the form of fire disturbance that causes the succession of ecosystems. Medium and high intensity fire disturbances completely destroy plants and re-run the entire ecosystem. The high frequency and large area of fire disturbance affect the information transmission, material circulation and energy flow of the ecosystem, which leads to the gradual degradation of the ecosystem. The second is the form of protection and promotion of ecosystem growth and development. Moderate and low intensity fires burn the litter on the ground surface, promoting circulation of nutrients throughout the ecosystem, reducing the frequency of fire disturbances and also obtaining favorable conditions for natural regeneration. From the time perspective, fire disturbance affects the rhythm of ecosystems, the laws of geochemical cycling, and the process of plant community renewal. From the aspect of space, fire disturbance will have great influence on the spatial distribution of the productivity in each part of the ecosystem, the regional characteristics and the land use way. It can be seen above that fire disturbance is of great significance to the ecosystem.
Eastern Mongolia is a more serious area of fire disturbance, which is a arid and semi-arid climate, and the fragile ecological environment makes the fire disturbance high-risk zone. In particular, in the recent 5 years, the grade of ecosystem fires climbed up and the pastoral areas became the most prominent. Weather climate, terrain features determine the spread of fire disturbance. The occurrence of fire disturbance is also closely related to human activities, and the frequency of fire disturbance in densely populated areas is higher. Statistics from the Mongolia resource network and the Mongolia national fire interference statistics table revealed that there were 2798 fire disturbances during 2009-2016 in this study area, accounting for $53 \%$ of the total number of fire disturbances in Mongolia, with an average of 349 times per year, of which human-caused fire $57.83 \%$, while unknown causes accounted for more than $30 \%$ of the fire disturbance. Human-caused fire disturbance is the most significant risk in the region. Fire disturbance has strong spatio-temporal pattern law, grasps and monitors the change characteristic of fire disturbance, depicts fire disturbance region and time difference, determines the spatiotemporal pattern rule of fire disturbance, to provides scientific basis for reducing the risk of fire disturbance.

Fire disturbance study using remote sensing data as the representative of MODIS data, although it is too coarse in the precise monitoring study, repeated observations two times a day increase the likelihood of obtaining more data without cloud. In recent years, in the study of fire disturbance monitoring on global or terrestrial scale, MODIS data explain various problems with space coverage and time continuity advantage. Better resolution data can detect all kinds of interference at the regional scale and has been used in many regional studies of fire disturbance mapping and evaluation in recent years. As a result

\footnotetext{
${ }^{*}$ Corresponding author.
} 
of a large number of historical archives (starting from 1970s) data can be obtained free of charge, as well as the predecessors of the research proposed a large number of automatic algorithms and data processing process, so that Landsat time series data focus on the application of a variety of interference detection research. Remote sensing technology has been applied to the mapping of fire disturbance ranges at different scales to evaluate the fire behavior and monitor the recovery after fire disturbance. Since the 1990s, in the study of the fire disturbance on the global scale, the main tendency is to use NOAA-AVHRR data mapping. In recent years, most researchers have applied SPOT-VGT and MODIS data. At the local regional scale, many of the fire disturbance monitoring algorithms have been applied to Landsat data. Through the analysis of remote sensing data, it is clear that the spatio-temporal pattern of fire disturbance and the degree of change.

\section{STUDY AREA, DATA AND METHODS}

\subsection{Study Area}

The research area of this paper is eastern Mongolia $\left(44.71^{\circ} \sim 50.82^{\circ} \mathrm{N}, 108.78^{\circ} \sim 119.98^{\circ} \mathrm{E}\right.$, mainly including Eastern province, Sukhbaatar province and Kent province). The area is located in central Asia (Fig. 1), belongs to the continental temperate steppe climate, the seasonal differences are more obvious. Annual average temperature from the northern $-4^{\circ} \mathrm{C}$ to the south $4{ }^{\circ} \mathrm{C}$, winter long and cold, January the lowest temperature reached- $27{ }^{\circ} \mathrm{C}$; short and dry in summer, July average temperature $17{ }^{\circ} \mathrm{C} \sim 18{ }^{\circ} \mathrm{C}$, northern and northwestern high mountain below $15{ }^{\circ} \mathrm{C}$, in the south near the ChinaMongolia border temperature is higher than $25^{\circ} \mathrm{C}$. The annual average precipitation decreases from north to south. The research area is rich in natural resources, covering mainly forest and grassland, $70 \%$ is flat grassland, and $30 \%$ is forest zone. There are more combustible objects in the surface area. Therefore, in the spring and autumn period, the eastern Mongolia became a serious area of fire disturbance.

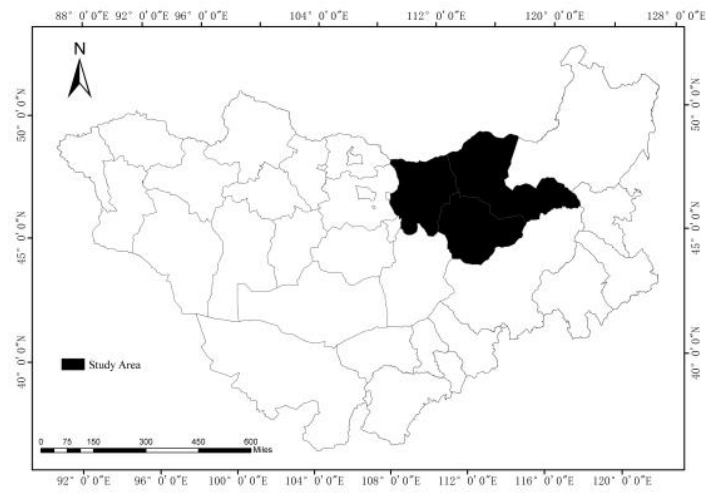

Figure 1. Study Area

\subsection{Data}

This paper uses the monthly level-3 gridded 500-meter fire burne area product to obtain the burned area data. The spatial resolution of the data is $1 \mathrm{~km}$, and the time resolution is 1 days. This study mainly extracted the location, area and date information of the burned area, which are included in the burndata layer of the product data. The land use data use Landsat7 TM remote sensing image data of August 2010, with the time resolution is 16 days, spatial resolution of $30 \mathrm{~m}$. The auxiliary data is applied to the administrative boundary of the eastern Mongolian region and the detailed statistics table of the cause of the regional fire disturbance. Using these boundary data to clip the remote sensing images, it is easy to count the number and area of fire disturbances in each province.

\subsection{Method}

First select the burned pixels from the burned data layer (interval data layer pixel value is 1 366). Using MRT, the 2scene images of every 8 days are mosaic and reprojection. The original sinusoidal projection of MODIS is converted to the albers projection, and the hdf format is converted to the Geotiff format. After the MRT processing, ArcGIS spatial analysis was used to obtain the study area images and extract the burntdata. HDF data from MCD45A1. Burntdata contains over-fire pixels and fire date, with fire date using julian day representation. Combined with the use of statistical methods and ArcGIS spatial analysis method for data analysis. The spatial distribution pattern of fire disturbance was obtained by using spatial analysis method. A statistical method is used to calculate the area and frequency of the fire disturbance from 2000 to 2014 in eastern Mongolia. Through the analysis of the above data, the spatio-temporal pattern of fire disturbance in eastern Mongolia was obtained.

\section{RESULTS}

\subsection{The Spatial Distribution of Fires Disturbance}

According to the spatial distribution of fire disturbance in eastern Mongolia from 2000 to 2014 (Fig. 2 a), the fire disturbance density is relatively high at the border. The distribution in the hinterland and the western part is less. Multiple zones are: the junction of the Eastern province and Inner Mongolia autonomous region, north of Eastern province and Kent province, Suhbaatar province southeast. In the west of Kent and Suhbaatar provinces there is no fire disturbance or less distribution.Among the three provinces, the fire distribution is the most in the Eastern province.

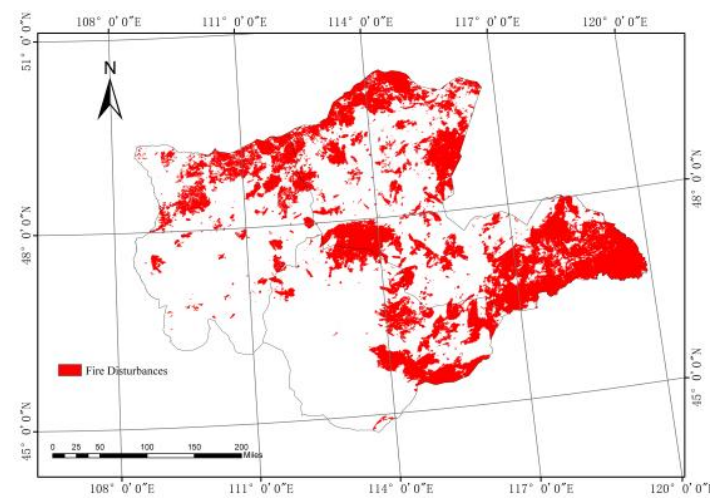

Figure 2.The Spatial Distribution of Fires (a) fire disturbance area

Figure 2(b) shows the frequency distribution of fire disturbance in eastern Mongolia from 2000 to 2014. According to the frequency of fire disturbance within 15 years, the study area is divided into three gradient zones: 1) highest frequency of fire disturbance area: there are mainly the junction of the Eastern province and Inner Mongolia autonomous region, north of the Eastern province and Kent province; That is, Tamusarg Prague, Halajkullah, Gurbanzhagara, and Chulung Hao Rao. Fire disturbance frequency reached 8 to 13 , but the distribution area is small; 2) higher frequency of fire disturbance area: The 
border between China and Mongolia and the northern region of the Eastern province. Mainly located in Tamusarg Prague, Harajgul, Gurbanjar Ghar, Balkan, Chulun Hao Rao special areas. A small amount of distribution in Erdene Chagan frequency reached 4 to 7 times; 3) Minimum frequency of fire disturbance area: It is distributed throughout the eastern Mongolia. The area of the most widely distributed, frequency of fire disturbance is $0 \sim 3$ times.

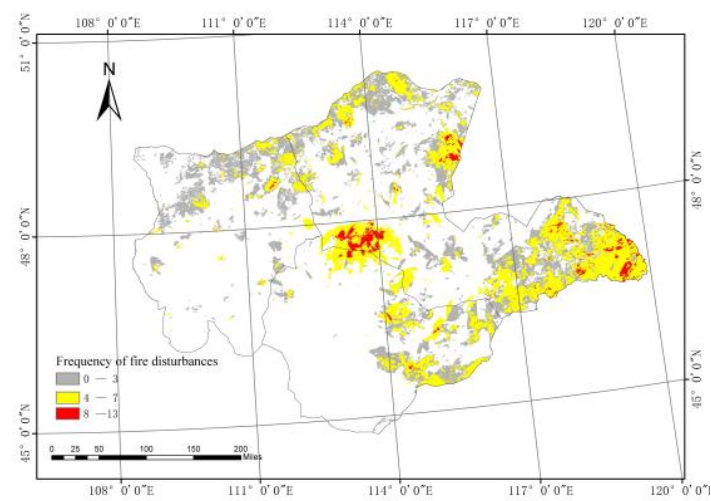

Figure 2.The Spatial Distribution of Fires (b) frequency of fire disturbances

\subsection{The Seasonal and Monthly Distribution of Fires Disturbance}

From Fig. 3(a), it can be seen that there are obvious interannual variations in the area of fire disturbance in the study area during the 2000-2014 years. The peak of fire disturbance appeared in 2003 with an area of $160.649 \mathrm{~km}^{2} .2002$ fire disturbance area is the smallest, about $6.657 \mathrm{~km}^{2} .2000-2003$ fire disturbance area has high and low peak interleaving phenomenon. In the past 2004-2010 years, there was a tendency to decrease, and significant increase in 2011-2014 years. In 2000, 2012, 2013 and 2014, the area of fire disturbance exceeded $100 \mathrm{~km}^{2}$, which was $139.385 \mathrm{~km}^{2}, 121.256 \mathrm{~km}^{2}, 139.606 \mathrm{~km}^{2}$ and $155.269 \mathrm{~km}^{2}$, respectively. According to the statistic chart, the province with the largest fire disturbance area is the Eastern provinces.

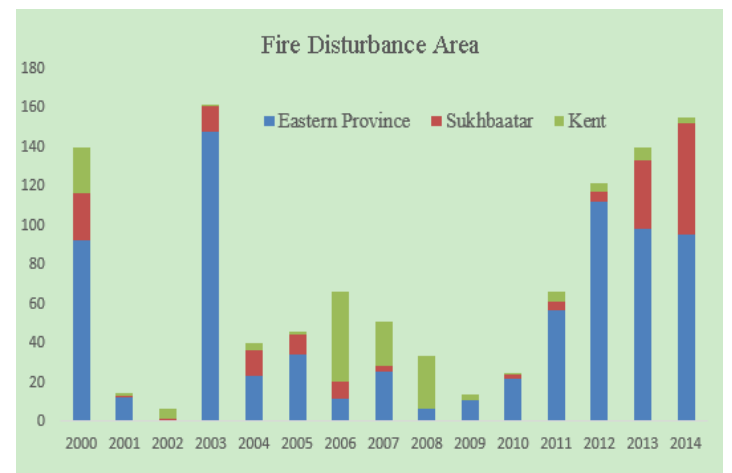

Figure 3. The Seasonal (a) Distribution of Fires

From the monthly variation of fire disturbance in eastern Mongolia (Fig. 3 b), it can be seen that the peak of fire disturbance area appears in spring and autumn, while the low value appears in winter and summer. Since 2000, the area of fire disturbance fluctuated greatly, and the maximum area of fire disturbance occurred in April 2012 was $61.471 \mathrm{~km}^{2}$. The area of fire disturbance in spring and autumn in 2000, 2003, 2004, 2012, 2013 and 2014 increased significantly. After a large area of fire disturbance, it has obvious decreasing trend when the region enters relative flameout period.

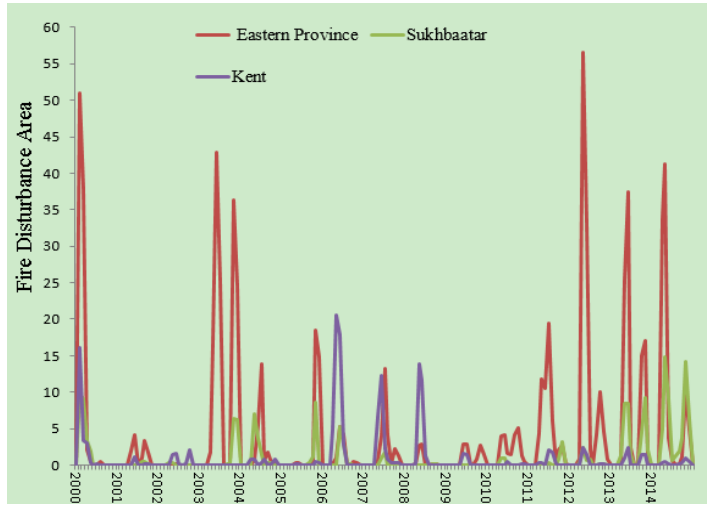

Figure 3. The Monthly (b) Distribution of Fires

\section{DISCUSSION}

This paper studies the fire disturbances in eastern Mongolia and finds that the regional fire disturbance has a significant spatiotemporal distribution pattern. The frequency of fire disturbance is basically consistent with the spatial distribution pattern. Fire disturbance showed spatial distribution regularity with different vegetation types. To a certain extent, the effect of vegetation on fire disturbances is reflected. In the eastern part of the study area, the vegetation cover is good with more combustibles. After the fire disturbance, the vegetation succession is rapid and the combustibles will accumulate again in a short time and cause fire disturbance. Therefore, the area and frequency of fire disturbance in this area are the highest, it divided into the highest frequency gradient area. The vegetation coverage in the hinterland is relatively small, the growth and development of plants are slow and the biomass is slightly less, so the area and frequency of fire disturbance are slightly lower. Due to severe desertification, low vegetation coverage and little accumulation of litter in the west, the fire disturbance is difficult to occur and spread. So the area and frequency of fire disturbances are the lowest. From the time angle, the fire disturbance in eastern Mongolia has remarkable time regularity. That is, the seasonal law of high in spring and autumn and low in summer and winter. The area has obvious high and low peak interleaving phenomenon in time distribution. On the other hand, the time law of fire disturbances is related to the accumulation of combustibles. The more the accumulating of the combustibles, the more easily the fire disturbances. After the fire disturbance, the amount of combustible material decreases, which leads to a relatively flameout period in the area. This explains the phenomenon of high and low peaks interleaving in the area of fire disturbance. The fire disturbance in the study area has an aggregate distribution, indicating that the fire disturbance does not occur randomly, is generated by a certain influence. Frequent human activities have caused fire disturbances in less vegetation areas. On the other hand, people's extinguishing ability and destructive behavior also show the effect of fire disturbance to some extent. Due to human resources and economic constraints, the fire disturbances management measures of Mongolia are relatively backward. Pastoralists tend to take their natural attitude towards fire disturbance. Therefore, the occurrence and spread of fire disturbances in eastern Mongolia is close to the natural level. 


\section{ACKNOWLEDGEMENTS}

This study was supported by the National Natural Science Foundation of China(Grant No.41601438, 41571489, $41771450,41501449,41461102$ and 41761101), the Foundation of the Education Department of Jilin Province in the 13th Five-Year project (Grant No. JJKH20170916KJ), the National Key Research and Development Project (Grant No. 2016YFA0602301) and Inner Mongolia Science and Technology Plan Project (201502113).

\section{REFERENCES}

Alves D B, Pérez-Cabello F, 2017.Multiple remote sensing data sources to assess spatio-temporal patterns of fire incidence over Campos Amazônicos Savanna Vegetation Enclave (Brazilian Amazon). Science of the Total Environment, 142, pp.601-602.

Andela N, Morton D C, Giglio L, et al. 2017.A human-driven decline in global burned area. Science, 1356, pp. 356(6345).

Coen J L, Schroeder W, 2013. Use of spatially refined satellite remote sensing fire detection data to initialize and evaluate coupled weather-wildfire growth model simulations. Geophysical Research Letters, 40(20), pp. 5536-5541.

Forghani A, Kazcrni S, Ge L, 2014. Wildland fire Behaviour simulations employing an: Integrated weather-topographicalfuel datasets and satellite remote sensing. International Journal of Geoinformatics, 10(4), pp.35-44.

Guha A, Kumar K V, 2012. Structural controls on coal fire distributions-Remote sensing based investigation in the Raniganj coalfield. Journal of the Geological Society of India, 79(5), pp. 467-475.

Kusangaya S, Sithole V B, 2015. Remote sensing-based fire frequency mapping in a savannah rangeland. South African Journal of Geomatics, 4(1), pp. 59-66.

Lentile L B, Holden Z A, Smith A M S, et al. 2006.Remote sensing techniques to assess active fire characteristics and postfire effects. International Journal of Wildland Fire, 15(3), pp. 319-345.

Magdalini Pleniou, Fotios Xystrakis, Panayotis Dimopoulos, et al.2012.Maps of fire occurrence-spatially explicit reconstruction of recent fire history using satellite remote sensing. Journal of Maps, 8(4), pp. 499-506.

Matthews B, Strand E K, Smith A M S, et al. 2016. Estimating fire radiative energy obscuration by tree canopy for remote sensing application. International Journal of Wildland Fire, in press.

Oliva P, Coen J, Schroeder W, 2013. Fire severity estimated from remote sensing data to evaluate the Coupled AtmosphereWildland Fire-Environment (CAWFE) model// AGU Fall Meeting Abstracts.

Ri J, Lee K S, 2015. Investigating the Spatial Characteristics of Forest Fire in North Korea using Remote Sensing and GIS// AGU Fall Meeting. AGU Fall Meeting Abstracts.

Sowmya S V, Somashekar R K, 2010. Application of remote sensing and geographical information system in mapping forest fire risk zone at Bhadra wildlife sanctuary. Journal of Environmental Biology, 31(6), pp. 969-974

Tonini M, Pereira M G, Parente J, et al. 2017. Evolution of forest fires in Portugal:from spatio-temporal point events to smoothed density maps. Natural Hazards, 85(3), pp.1489-1510.

Tonini M, Pereira M G, Parente J, 2017. Spatio-temporal evolution of forest fires in Portugal// EGU General Assembly Conference. EGU General Assembly Conference Abstracts.

Wei Z, Shao J, Meng W, et al. 2013. Dynamic monitoring and analysis of grassland fire based on multi-source satellite remote sensing data. Journal of Natural Disasters, 22(3), pp.54-61. 